\title{
Solving the Problem of Threats to Care for Medicaid Beneficiaries with HIV/AIDS
}

\author{
Danielle R.Noll ${ }^{\dagger}$
}

Danielle Noll is a master of public administration candidate studying health care policy. Ms. Noll is a Presidential Administrative Fellow at The George Washington University, where she received her bachelor's degree in international affairs in May 1994. She recently completed an academic internship with the Office of National AIDS Policy.

\section{Introduction}

In an effort to stem their share of rising Medicaid expenditures, states are searching for innovative methods to contain the costs of health care for beneficiaries. Placing these beneficiaries in managed care arrangements has become an increasingly popular solution. In their haste to implement these programs and achieve cost savings, however, states may compromise the quality of care to which beneficiaries are entitled, specifically those with HIV/AIDS for whom potential changes in the quality of care are life-threatening. Since HIV/AIDS requires a comprehensive system of treatment to ameliorate the patient's conditions and prolong life as well as prevent the spread of the epidemic, this population does not fit easily into the managed care framework of controlled access to services and preventive care.

This article examines the multi-faceted issue of adequate health care for HIV/AIDS patients in the context of managed care programs for state beneficiaries of Medicaid. Three potential solutions are presented: the expansion and stimulation of existing innovative state programs; the establishment of specific federal requirements for state Medicaid managed care programs; and the creation of a new federal program for HIV/AIDS patients. These options are evaluated on the quality of care provided, political and administrative feasibility, and cost-effectiveness. Because quality of care is both a paramount concern for patients and advocacy groups and an important element in cost containment for HIV/AIDS treatment, quality issues are weighted more heavily than feasibility or cost-effectiveness.

The policy recommendations presented are provisional in light of possible changes in Medicaid. This analysis assumes that the Medicaid program will continue to exist as an entitlement program jointly funded by the federal and state governments. Current Congressional budget legis- lation, however, could fundamentally affect the system by reducing Medicaid spending or altering the Medicaid entitlement. Such action would shift additional costs and responsibilities to the states, though budget legislation may provide states wider latitude in establishing programs for Medicaid beneficiaries. Whatever the budget scenario, federal administrators will play a smaller role in the policy debate, as states implement innovative programs.

Given federal funding uncertainty and the rising trend of managed care at the state level, establishing federal requirements for Medicaid managed care programs serving HIV/AIDS patients is the best policy choice. All criteria are satisfied by this option which promotes uniform standards of care and accountability to HIV/AIDS patients.

\section{Background}

Since the first cases of acquired immunodeficiency syndrome (AIDS) were reported in 1981, more than 500,000 persons in the United States have been diagnosed with the disease, and more than half of this number have died. ${ }^{1}$ AIDS is now the leading cause of death for Americans between the ages of 25 and 44 and claims one life every eight minutes. ${ }^{2}$ Additionally, more than one million people are reportedly infected with human immunodeficiency virus (HIV), the virus which causes AIDS.

Once infected with HIV, an individual can survive at least three and as many as thirteen years before contracting AIDS. For this reason, HIV/AIDS is treated as a chronic disease with episodes of acute illness. ${ }^{3}$ Treatment requires a comprehensive and coordinated regimen of care, which. can range from counseling and routine primary care visits to prescription drugs, hospitalization, investigational treatments, home or hospice care at the late stages of the disease, and support services if the patient becomes disabled 
(i.e., transportation and housing). The duration, frequency, and cost of such treatment is difficult to predict and varies widely with each individual, but the average lifetime cost of treating a person with HIV from the time of infection until death is estimated at $\$ 119,000$. This cost does not include additional non-medical treatments (i.e., substance abuse, counseling, and support services) which may also be required throughout the illness.

\section{Given federal funding uncertainty and the rising trend of managed care at the state level, establishing federal requirements for Medicaid managed care programs serving HIV/AIDS patients is the best policy cboice.}

Persons with HIV/AIDS often face high health insurance premiums or lack health insurance coverage altogether, leading to dependence on public health insurance, such as Medicaid and Medicare, ${ }^{5}$ or community services from health centers or non-profit organizations." Seventy percent of the cost for HIV/AIDS treatment are borne by Medicaid, a jointly-funded federal and state insurance program. ${ }^{7}$ Medicaid covers the health care costs of nearly 50 percent of adults with AIDS and more than 90 percent of children living with AIDS at an estimated annual cost of $\$ 2.6$ billion. ${ }^{8}$ The cost of providing treatment to this population and overall program costs are expected to increase as the demographics of HIV expands among poverty populations."

The fiscal implications of rising Medicaid costs on state budgets spurs the current debate on an appropriate policy framework for the delivery of health care to HIV/AIDS patients. Although expenditures on HIV/AIDS patients comprise only 2 percent ( $\$ 2.6$ billion) of the entire Medicaid budget, ${ }^{10}$ the impact on Medicaid expenditures is considerable in states affected most by the epidemic: New York, California, Florida, and Texas. ${ }^{11}$ These states accounted for 57 percent of the total reported AIDS cases in $1992 .^{12}$

The ability of managed care arrangements ${ }^{13}$ to provide adequate care for people with HIV/AIDS is questionable because managed care plans typically have a financial incentive to contain or reduce the costs of services. ${ }^{14}$ Managed care organizations (MCOs) provide cost-effective primary and preventive care by predicting and controlling the utilization of expensive services for enrollees. These practices may conflict with the unique treatment needs of the HIV/AIDS population, as the frequency and costs of these services are unpredictable. ${ }^{15}$

Managed care organizations face financial risk in providing care for HIV/AIDS populations. In order to reduce such risks, MCOs may impose limitations on the types of care provided or deny coverage for these populations altogether. For an HIV/AIDS patient, such limitations may be the difference between home treatment or hospitalization for a critical condition. ${ }^{16}$ For this reason, health administrators and advocacy groups contend that Medicaid beneficiaries with HIV/AIDS should not be subject to the same referral process or waiting period typically required in managed care plans, as these delays may further jeopardize the patients' delicate health. These stakeholders favor unrestricted access to specialty care for people with HIV/AIDS, so that the individual may choose to continue under the care of a specialty physician without referral from a primary care provider, a necessary pre-condition for nonHIV/AIDS patients in MCOs.

Advocacy groups have specifically questioned the ability of managed care organizations to provide adequate and costeffective treatment for people with HIV/AIDS. In October 1995, New York City was criticized by local AIDS advocates for its proposal to place its Medicaid beneficiariesincluding approximately 25,000 people with HIV/AIDS-in managed care arrangements. Based on its survey of Medicaid managed care plans in New York City, advocacy groups reported that these MCOs were neither knowledgeable nor experienced in clealing with AIDS-related illnesses. ${ }^{17}$ In order to provide high-quality care, MCOs and other managed care arrangements must establish comprehensive, coordinated systems of care, including adequate networks of trained specialists and a broad array of services uniquely required during the stages of HIV/AIDS. Such systems of care should also coordinate with public health agencies, health care providers, and communitybased and voluntary organizations that provide both medical and non-medical services. ${ }^{18}$

\section{Options}

Proposed policy options are: expanding and stimulating existing innovative programs, establishing specific federal guidelines for Medicaid managed care programs, and creating a new federal program for HIV/AIDS patients.

\section{Option 1: Expand and Stimulate Existing Innovative Programs}

The current vehicles for innovations for Medicaid managed care at the state level have been provisions in the Medicaid 
Act (known as the Section 1115 "Research and Demonstration," 1915(b) "Freedom of Choice," and 1915(c) Homeand Community-based waivers), which enable states to design unique programs for Medicaid beneficiaries by suspending some of the statutory requirements of the Medicaid program. ${ }^{19}$

\begin{tabular}{c}
\hline Since the first cases of acquired \\
immunodeficiency syndrome (AIDS) \\
were reported in 1981, more than \\
500,000 persons in the United States \\
bave been diagnosed with the disease, \\
and more than balf of this number \\
bave died.
\end{tabular}

In establishing waiver demonstration programs, many states have focused on the "healthy" sectors of the populationnamely women and children-since studies of some managed care programs have shown some improvements in cost-effective, high-quality care for this population. ${ }^{20}$ Most approved waiver programs have exempted beneficiaries with HIV/AIDS; however, several states have targeted these beneficiaries through 1915(c) "Home- and CommunityBased" waivers which enable states to provide a variety of home- and community-based care to Medicaid beneficiaries under a capitated system. ${ }^{21}$ Under the traditional fee-for-service model, these services would be provided in the hospital or a nursing home, which are often more costly settings.

Since both the 1915(b) and (c) waiver programs have potential applicability for HIV/AIDS patients, and, in some cases, already provide services for these populations, the Health Care Financing Administration (HCFA), the federal agency which oversees Medicaid, could offer further incentives to states (i.e., special grants or expedited waiver approval) to expand current waiver programs or establish new waiver programs which target people with HIV/AIDS. In fact, HCFA has already drafted a 1915 (c) waiver prototype which outlines the requisite information states need for the waiver approval. State use of this standardized form will reduce the application time and resources, streamline the application process, and expedite waiver approval. Additionally, the quality standards used to evaluate these programs could be applied to larger, state-wide programs which serve HIV/AIDS patients.

Innovative strategies in the private sector should not be ignored. The Community Medical Alliance (CMA) of Boston, Massachusetts, has developed a high-quality, cost- effective managed care model for people with AIDS or other severe disabilities. ${ }^{22}$ By enabling nurse practitioners to provide enhanced case management and allowing physicians more independence, CMA has been able to provide effective care for people with chronic illnesses, while reducing the capitation rate from $\$ 1,900$ to $\$ 1,500$ for the severely disabled, ${ }^{23}$

Under this option, HCFA would study the CMA program data, standardize the system, and establish state pilot projects designated for HIV/AIDS patients. HCFA would maintain federal oversight of these programs and create centralized standards while facilitating state flexibility in program design.

\section{Option 2: Establish Specific Federal Requirements for State Medicaid Managed Care Programs}

The Office of National AIDS Policy, the Gay Men's Health Crisis (GMHC), and the AIDS Action Council (AAC) $)^{24}$ have proposed guidelines to be considered in evaluating any state Medicaid managed care program. The Office of National AIDS Policy, as an intermediary between advocacy groups and federal and state administrators, could create a forum for discussion of such guidelines. ${ }^{25}$ HCFA could then adopt these suggestions as requirements for states' Medicaid managed care programs. Assuming that the Medicaid program is not converted to a block grant, states' waiver proposals would have to meet these criteria in order to receive federal approval. Any state waiver proposal that does not satisfy these criteria would not be approved. The state would continue to provide care for beneficiaries with HIV/AIDS under current Medicaid arrangements.

The Office of National AIDS Policy has proposed guidelines with regard to Medicaid managed care programs for people with HIV/AIDS. ${ }^{26}$ GMHC and AAC have also submitted a list of proposed criteria to be used by HCFA in evaluating Medicaid managed care programs. ${ }^{27}$ In general, both groups support the improvement of care for people with HIV/AIDS through managed care organizations, but favor gradual implementation based on previous experience and thorough program evaluation.

These requirements would specifically address the concerns of people with HIV/AIDS, including the types of services offered, the proposed provider network, the referral process for specialty care, and adequate and accurate program evaluation. The primary focus of such requirements should be the quality of care for HIV/AIDS patients. Additionally, these requirements may compel states to address regional and state-specific obstacles to care. 


\section{Option 3: Create a New Federal Program for HIV/AIDS Patients.}

The Office of National AIDS Policy has proposed a jointlyfunded capitated program which would use existing state and federal funds from the Ryan White CARE Act and Medicaid to provide care for HIV/AIDS patients. ${ }^{28}$ Presently, the Ryan White CARE Act prohibits grantees from using funds to finance inpatient services for people with HIV/AIDS. ${ }^{29}$ Thus, while grantees can provide funding for outpatient services, these organizations must rely on their own resources to cover the costs of inpatient care.

By establishing a joint program, government administrators, community-based organizations, and advocacy groups could establish a more uniform, comprehensive system of care. This option would require coordination between HCFA and the Health Resources Services Administration, the federal agency which allocates Ryan White CARE Act funding. ${ }^{30}$ These agencies would then establish a funding system for Ryan White grantees and state governments that would keep the funding streams separate, so that Ryan White money would be used only for outpatient services.

\section{Criteria}

In identifying and evaluating the options that will provide the best and most cost-effective care for people with HIV/AIDS, administrative agencies, advocacy groups, and providers have identified several criteria that must be satisfied. The most desirable policy option must provide highquality care and be politically and administratively feasibie and cost-effective.

\section{Quality of Care}

Advocacy groups and community-based organizations maintain a strong commitment to improving the quality of care for people with HIV/AIDS, and will not support any option which reduces the standard of care for this population. Advocates and HIV/AIDS patients evaluate quality based on the following factors: an established continuum of care; knowledgeable health care personnel; access to specialty services; and quality assurance through comprehensive program monitoring.

The quality of care under managed care arrangements ${ }^{31}$ is of paramount concern for people with HIV/AIDS for two reasons. First, advocacy groups and administrators worry about the lack of previous experience on the part of managed care organizations (MCOs) in providing care to people with HIV/AIDS. Second, under capitated Medicaid programs, MCOs may reduce the number of available services in an effort to reduce the costs of care.
Placement of Medicaid beneficiaries with HIV/AIDS in managed care arrangements should be accomplished in a manner least disruptive to the existing care relationships for these patients. ${ }^{32}$ Effective, high-quality care of HIV/AIDS patients requires continuous monitoring by the provider of the patient's progress and treatment plan. Any care arrangement which results in forced change of provider may disrupt this continuum of care.

\section{Placement of Medicaid beneficiaries with HIV/AIDS in managed care. arrangements should be accomplisbed in a manner least disruptive to the existing care relationships for these patients.}

Care providers must be knowledgeable about the various approaches to HIV/AIDS treatment and prevention. Due to the protean nature of the disease, the standard of care for the treatment of HIV/AIDS changes rapidly, and often relies upon experimental interventions, including the "offlabel" use of prescription drugs. ${ }^{33}$ MCOs should establish broad networks of trained specialists with knowledge of HIV/AIDS and the various ways in which the disease presents itself. Community-based providers and advocacy groups that provide essential non-medical services should also be included in this network.

Access to care, specifically specialty care, is an important issue; HIV/AIDS patients must be able to receive care when necessary in order to effectively treat their disease. If essential services are not provided through the managed care arrangement, HIV/AIDS patients will be forced to either pay for the treatment themselves or seek care from charity organizations, community-based organizations, or other public providers. Health plans should include the broad array of treatment and support services required by HIV/AIDS patients during their illness. ${ }^{34}$ Care should be included in a variety of settings: inpatient care of opportunistic infections, home-based infusion therapy, or hospice care, for example. ${ }^{35}$

In order to ensure that the above criteria are being met, states should evaluate managed care arrangements using basic outcome measures; the incidence of opportunistic infections in people with HIV, the incidence of AIDS in people with HIV (i.e,, how long after the patient is diagnosed with HIV does s/he contract AIDS?), and the life span of patients with HIV/AIDS. ${ }^{36}$ Careful evaluation and monitoring of managed care plans is especially critical for 
HIV/AIDS patients because of the financial incentive to limit the use of expensive-but often necessary-services.

\section{Feasibility}

The best policy option must be administratively feasible, acceptable to all stakeholders, and politically viable. HIV/AIDS patients require medical and non-medical services provided by a combination of private providers, community-based organizations, and federally qualified health centers (FQHCs). Community organizations and FQHCs, which are most familiar with the concerns of the HIV/AIDS population and the types of medical and non-medical services required, contribute valuable knowledge and experience to the policy discussion about the health care delivery for HIV/AIDS patients.

Since Medicaid is a joint federal-state program, the support of HCFA is fundamental to the success of a policy. ${ }^{37}$ HCFA administrators are wary that expanded state authority may yield rapid enrollment of Medicaid beneficiaries in managed care plans. From a federal agency perspective, such autonomy and hasty policy decisions would compromise the quality of care for HIV/AIDS patients.

Although HCFA formulates federal Medicaid policy, implementation occurs in fifty states, each of which has a different Medicaid program. In general, state administrators express strong resistance to further fecleral oversight of the Medicaid program, contending that current requirements are bureaucratic and inhibit innovation. While state administrators appreciate the flexibility of Section 1115 and 1915(b) waiver programs, many contend that the federal requirements remain an administrative burden. Thus, administrators favor limited federal oversight of the Medicaid program.

\section{Since Medicaid is a joint federal-state program, the support of the Health Care Financing Administration (HCFA) is fundamental to the success of a policy.}

Support from advocacy groups and community-based organizations is also essential, as these organizations provide or coordinate social services for HIV/AIDS patients. Since many of these organizations are also Ryan White grantees, they may contribute valuable financial and administrative support to effective care for HIV/AIDS patients. The interests of these groups are best represented by two advocacy groups, the Gay Men's Health Crisis (GMHC) and the AIDS
Action Council (AAC).

Administrative feasibility is an important sub-criterion on several levels. Evaluation of administrative feasibility discloses the length of time and amount of funding necessary to implement the program, the legal and procedural obstacles which must be addressed prior to implementation, and the appropriate balance between program requirements and existing resources. Great differences among state Medicaid programs increase an alternative's effect on resource allocation, provider participation and certification, beneficiary enrollment, and program evaluation.

\section{Cost-Effectiveness}

The cost-effectiveness criterion determines whether proviced services are comparable or better than those previously provided as well as actual costs and benefits involved. An important component in evaluating the alternative for possible cost savings is accurate and thorough program evaluation. ${ }^{38}$ Any alternative must provide a framework for accurate data collection and program evaluation to determine the costs of services and evaluate the financial benefits of managed care for HIV/AIDS populations. The importance of measuring the financial impact of managed care arrangements is amplified by the quality of care criterion: quality will yield lower long-term costs of care for HIV/AIDS patients.

\section{Evaluation of Options}

\section{Option 1: Expand and Stimulate Existing Innovative Programs}

This option addresses the quality of care criterion by applying the current standards for waiver proposals to innovative programs as well. These standards would require states to establish a continuum of care, provide knowledgeable health care personnel, enable access to services, and promote quality assurance through program monitoring. However, while the use of such standards would establish some degree of uniformity among waiver programs, the option would encourage further variability among state Medicaid programs. Not all states possess the resources to expand existing programs or create innovative pilot programs; these states would instead choose to continue to care for HIV/AIDS patients under the current Medicaid benefits package. Thus, the quality of care for Medicaid beneficiaries would continue to vary widely across state boundaries.

Both the existing waiver programs and the innovative pilots included in this option have received support from federal and state administrative agencies, the office of 
National AIDS Policy, advocacy groups, and communitybased organizations. States particularly enjoy the flexibility in designing special programs to meet the unique needs of their HIV/AIDS populations. Additionally, other stakeholder groups have applauded states' efforts to focus on HIV/AIDS patients.

The option's use of existing program standards and a prototype waiver to streamline the application process and expedite waiver approval would relieve some of the administrative burden of evaluating waiver proposals. However, federal administrators would still be required to evaluate states' innovative pilots on a case-by-case basis, a process which would severely strain federal resources. Additionally, this option would require state administrative agencies to supply additional evaluative data, some of which is (in some states) not currently available.

The option's overall impact on Meclicaid expenditures is difficult to determine. The Office of National AIDS Policy, federal and state administrative agencies, advocacy groups, and community-based organizations are not convinced that managed care arrangements can provide cost-effective treatment, even for "healthy" populations. Although capitation under managed care can provide immediate cost savings, if managed care limits costly but necessary services (i.e. hospitalization), the use of these services may negate any short-term savings. This situation would be especially problematic for HIV/AIDS patients because such utilization control eliminates uniform standards of care.

\section{Option 2: Establish Specific Federal Requirements for State Medicaid Managed Care Programs}

Establishing federal requirements would best address the issue of quality of care by ensuring that states provide a continuum of care and a provider network of knowledgeable health care personnel, access to specialty care, and quality assurance through program monitoring. This option would eliminate the disparity among state programs by establishing uniform standards for all Medicaid managed care programs that include HIV/AIDS patients. Although states would still have the flexibility to design innovative waiver programs, administrators have to adhere to specific guidelines for HIV/AIDS patients.

This option has received support from several governmental and interest group stakeholders. Enabling all interest groups to participate in the process would ensure that the final requirements would be acceptable to all stakeholders. State administrative agencies, however, may resent additional requirements for an already bureaucratic program. In the event that states resist further requirements, federal administrators could provide additional financial and technical support to enable states to meet the new requirements.

With regard to administrative feasibility, this option would require sophisticated data collection at the state and federal levels and more thorough evaluations of state waiver proposals by HCFA administrators. Additional resources from both the federal and state governments would be needed if more focused compliance oversight is required. These costs could be offset by interest groups' earlier efforts to draft possible guidelines which could then be used as a starting point for federal requirements. Also, federal technical support to states could alleviate some of the administrative burden of compliance with the requirements.

As previously mentioned, costs are heightened at the federal level by increased administrative oversight and at the state level by the requirement of more thorough data collection and policy evaluation. States may incur additional costs in providing additional benefits necessary to satisfy the requirements. These costs could be balanced by savings generated by managed care arrangements. Also, evaluation data would be valuable in assessing the impact of managed care arrangements on Medicaid beneficiaries and implementing cost-effective measures. Thus, administrators should realize that the short-term costs associated with the option could outweigh the long-term benefits, of which the most important is an improvement in the quality of care for Medicaid beneficiaries with HIV/AIDS.

[C]osts are beightened at the federal
level by increased administrative
oversight and at the state level by the
requirement of more thorough data
collection and policy evaluation.

Option 3: Create a New Federal Program for HIV/AIDS Patients

Establishing a unique federal program would allow the Office of National AIDS Policy, HCFA, HRSA, state Medicaid agencies, and Ryan White grantees to custom design a managed care program for people with HIV/AIDS. Participants would be able to fully address the quality of care criterion by establishing a continuum of care, creating adequate provider networks, ensuring access to services, and coordinating quality assurance mechanisms. Additionally, the option would promote uniformity through one federal program instead of 50 different state programs. 
Although the option has received political support from advocacy groups and relevant administrative agencies, administrative support may not be as forthcoming for the simple reason that the required efforts may not yield the desired results. Unlike the previous options, which work with existing programs, this policy alternative would involve the creation of an entirely new program, including a new monetary mechanism that would need to keep the funding sources separate yet coordinated among fifty state Medicaid programs and as many Ryan White grantees.

Considerable effort would be required on the part of all interested parties. Additional federal staff and resources would be required to design, establish, and implement the program. Federal administrators would have to coordinate and train several different staffs at the state and local levels, as well as relevant advocacy groups, Ryan White grantees, and other community-based organizations. These groups, in turn, would have to expend considerable time and resources in order to implement the administrative mechanisms.

In terms of cost-effectiveness, the coordination of Ryan White and Medicaid funds may reduce the current overlap of funding and services and reduce state expenditures on Medicaid beneficiaries with HIV/AIDS, but ultimately at a higher cost to the federal government. Lack of data about the program's impact raises uncertainties about the program's performance and possible cost savings. Thus, the option may sacrifice the quality of care for HIV/AIDS patients with little or no guarantee that cost savings would be achieved. Until more specific information about this type of program is available, the option presents an unjustifiable risk to the quality of care for HIV/AIDS patients.

\section{Recommendation}

The establishment of specific federal requirements for state Medicaid managed care programs is the preferred policy option for several reasons. First, federal requirements established by all stakeholders would specifically address the primary issue of high-quality care for HIV/AIDS patients, and would ensure that the special needs of this population are met by states' Medicaid managed care programs.

Specifically, the requirements would address each of the components of the quality of care criterion: an established continuum of care; knowledgeable health care personnel; access to specialty services; and quality assurances through comprehensive program monitoring. These standards would eliminate the disparity among state Medicaid managed care programs while allowing states to retain flexibility and autonomy in designing such programs.
In addition to satisfying the quality of care criterion, the recommended policy option is also administratively feasible, acceptable to most of the stakeholders, and politically viable. The federal requirements, though established by HCFA, would be determined through discussions with all interested parties. Federal administrators, advocacy groups, and community organizations strongly support the establishment of federal requirements. In fact, several of these groups have already outlined possible criteria to be used in evaluating proposed Medicaid managed care programs for HIV/AIDS patients. However, state administrators who generally favor fewer federal mandates may object to further bureaucratic Medicaid processes. In the event that states express strong opposition to these guidelines, federal administrators could provide additional financial and technical support to assist states with compliance.

The establishment of specific federal
requirements for state Medicaid
managed care programs is the preferred
policy option for several reasons.

Another central factor in the issue of feasibility is the option's effect on administrative procedures. Establishing federal requirements would create additional costs for federal and state governments to establish accurate clata collection systems and more thorough evaluations of state programs. However, such short-term costs may be offset by long-term gains in data collection and program evaluation. Additionally, federal aid would relieve some state administrative costs. Finally, administrators should realize that such costs will yield the most important benefit: improved quality of care for Medicaid beneficiaries with HIV/AIDS.

Thus, the establishment of federal guidelines, while universally not the optimal solution for all stakeholders, is the best option at this time. In comparison to the alternatives, this option clearly meets the quality of care criterion while also having the lowest impact on administrative procedures and the most feasible design.

Although the remaining two options adequately address the criterion of quality of care, both have serious deficiencies. The expansion and stimulation of existing innovative state programs, though politically viable in many ways, does not fully address the need for uniformity among state Medicaid programs. In fact, the option may encourage even more disparity among states. Although the option proposes the formation of uniform standards for these innovative programs, not all states will choose to support 
such programs, and the care for HIV/AIDS patients would continue to vary widely from state to state. This disparity would further complicate data collection and program evaluation, one of the primary goals of the option.

Despite these deficiencies, expansion and stimulation of existing innovative programs may be viable as a bridge to federal requirements by encouraging state innovation in program design and providing a model from which future guidelines could be developed. This option would continue to provide states flexibility in designing programs while ensuring that such programs do not compromise the quality of care for HIV/AIDS patients.

The creation of a new federal program for HIV/AIDS patients is not a viable option at this time. Although the option would address the quality of care criterion and promotes uniformity among state programs, significant administrative obstacles may prevent the option from producing the desired results. First, this option requires the creation of an entirely new program, including a unique funding mechanism. Second, the option relies heavily on the coordination of several different stakeholders, including federal and state administrators, advocacy groups, and communitybased organizations. These stakeholders would be required to expend considerable resources in order to implement the option and such efforts may not produce the desired results. Lastly, and most importantly, this uncertainty poses an unjustifiable risk to the quality of care for HIV/AIDS patients.

\section{Conclusion}

The present policy discussions regarding Medicaid pose significant risks to HIV/AIDS patients. State administrators, desperate to contain increasing Medicaid expenditures, are shifting Medicaid beneficiaries into managed care arrangements at a rapid pace. Although preliminary data suggest that such arrangements can provide adequate and costeffective preventive and primary care services for "healthy" Medicaid beneficiaries, their ability to provide the same standard of care for HIV/AIDS patients is questionable. Because managed care plans have a financial incentive to limit the utilization of specialty services, such arrangements could seriously compromise the quality of care for HIV/AIDS patients with potentially dangerous results.

Although the waiver process provides states with the flexibility to design innovative and experimental solutions to increasing Medicaid expenditures, the wide variability among state Medicaid programs prevents the establishment of uniform standards of care for Medicaid beneficiaries with HIV/AIDS. Such standards are necessary to ensure a minimal level of benefits for HIV/AIDS patients.

Differences among states' programs also inhibits accurate data collection. Unless this issue is fully addressed, neither federal nor state administrators will be able to determine the costs and benefits of managed care programs for HIV/AIDS populations.

Establishing federal requirements presents the best opportunity to improve the quality of care for HIV/AIDS patients. Although such requirements may not be acceptable to all stakeholders, especially states, this option is the only method of reducing the variability between states' Medicaid managed care programs. Federal requirements will enable the collection and evaluation of comprehensive, uniform data, which could stimulate innovative approaches by state Medicaid programs, local governments, and public-private partnerships. $\star$

\section{Notes}

II would first like to thank my article editor, Jennifer Hicks, for her insight, expertise, and patience, and my associate editor, Lauren Giniger, for her diligent research assistance and comments. My thanks also goes to Heather Johnston and Professor Jill Kasle, for their continued support and guidance. Lastly, I would like to thank Jeff Levi and Kala Ladenheim for their support and encouragement.

The views expressed in this article are of the author and do not represent the policy or position of the Office of National AIDS Policy.

"The Centers for Disease Control and Prevention estimates that a total of 501,310 persons in the United States have been diagnosed with the disease. Approximately 62 percent $(311,381)$ of those diagnosed with AIDS have died. (Department of Health and Human Services, Centers for Disease Control, Morbidity and Mortality Weekly Report, 44, no, 46 [Washington, D.C.: Department of Health and Human Services], 1.)

${ }^{2}$ "The HIV/AIDS Pandemic-Why Continued Funding is Needed," (Office of National AIDS Policy, internal document, photocopied).

${ }^{3}$ Generally, literature on managed care and Medicaid includes HIV/AIDS patients as part of the chronically ill and/or disabled populations. (Robert Buchanon and Fred Kircher, "Medicaid Policies for AIDS-Related Hospital Care," Health Care Financing Review 15, no. 4 [1994]: 33-41.)

${ }^{4}$ Fred J. Hellinger, "The Lifetime Cost of Treating a Person with HIV." Joumal of the American Medical Association 270, no, 4 (1993): 474. 
5nce a person with AIDS becomes disabled, the individual receives Social Security Disability (SSDI) benefits and is automatically eligible for Medicaid. Other persons with AIDS become eligible when the cost of care erodes their savings (the concept of "spending down to Medicaid") or they lose private, employer-based coverage due to retirement or disability. (Department of Health and Human Services, Health Care Financing Administration, Medicaid and AIDS [Washington, D.C.: Department of Health and Human Services, 1995] .)

${ }^{6}$ In areas of the country where the pool of providers and/or specialists willing to treat Medicaid beneficiaries with HIV/AIDS is particularly inadequate, a network of community providers, such as federally-qualified health centers and nonprofit organizations, provides specialized care to the HIV/AIDS population, (Gay Men's Health Crisis and AIDS Action Council, Review of State Medicaid Managed Care Waiver Applications, [New York: Gay Men's Health Crisis and AIDS Action Council], 4.)

${ }^{7}$ Medicaid is authorized in the Social Security Amendments of 1965, Pub. L. No. 80-97 (adding 42 U.S.C. 1315). Medicaid entitles eligible individuals to specific services, such as hospital stays, physician care, nursing facilities, and laboratory and $\mathrm{x}$-ray services; other benefits, such as prescription drugs, dental care, and eyeglasses are considered optional. (Jane Perkins and Michele Melden, Section 1115 Medicaid Waivers: An Advocates Prime, [National Health Law Program, October 1994], 5.)

${ }^{8}$ Medicaid's Role for Persons with HIV/AIDS (Washington, D.C.: The Henry J. Kaiser Family Foundation., 1994).

Jjeff Levi, Deputy Director; Office of National AIDS Policy, Memo to Office of National AIDS Policy Director Patricia Fleming, June 22, 1995.

${ }^{10}$ The Office of National AIDS Policy reported federal expenditures of $\$ 1.5$ billion in fiscal year 1994. The $\$ 2.6$ billion clollar estimate assumes an average of 57 percent federal match of state dollars." (Medicaid's Role for Persons witb HIV/AIDS [Washington, D.C.: The Henry J. Kaiser Family Foundation, 1994!.)

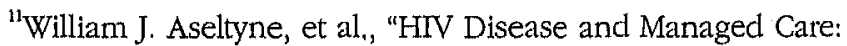
An Overview," Journal of Acquired Immune Deficiency Syndromes and Human Retrovirology 8, supplement no. 11 (1995).

${ }^{12}$ Ibicd., $\mathrm{S} 20$.

${ }^{13}$ In the following policy discussion, the term "managed care" applies to a system of health care in which providers and payers establish a contractual arrangement to provide health care to individual patients. (Policy Brief: The Kaiser Commission on the Future of Medicaid [Washington, D.C.: The Henry J. Kaiser Family Foundation, June 1995], 3.) Unlike the fee-for-service model, these arrangements offer incentives to providers to control utilization of specialty services and reduce the costs of care for enrollees. This utilization control, also known as "gatekeeping," is usually performed by a primary care physician who approves specialty services, Managed care arrangements also attempt to reduce costs through capitation, in which states pay a monthly fee for each patient to providets, thus giving providers the incentive to reduce the costs of services. (Aseltyne, S12.)

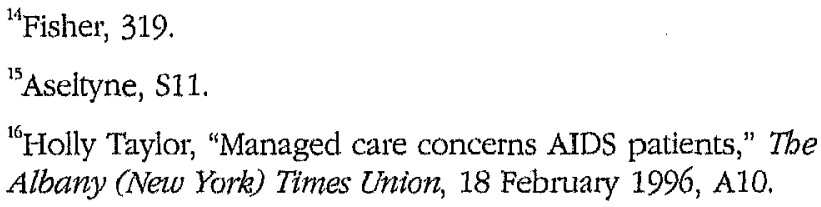
The New York Times, 4 October 1995, B1-B3.

${ }^{14}$ Aseltyne, S17.

${ }^{11}$ As of February 1996, 49 states have implemented some form of managed care and this trend is likely to continue. The Secretary of Health and Human Services is authorized to waive the mandatory provisions of the Medicaid Act under Sections 1915 and 1115 of the Social Security Act (42 U.S.C. 1396(b) and 1315(a) respectively). The 1915(b) "Freedom of Choice Waiver" allows states to require mandatory enrollment of Medicaid beneficiaries in a managed care program and restrict the providers from whom recipients receive Medicaidcovered services. The managed care arrangement for these waiver programs, however, varies from state to state, and only a few programs target HIV/AIDS patients. Section 1115 allows states to establish an experimental, pilot, or demonstration project for three to five years (Perkins, 5). Programs operating under this waiver authority have primarily targeted the "healthy" sectors of the Medicaid population, namely, those recipients who require basic primary care and preventive services. Examples include Tennessee's TennCare, the Oregon Health Plan, and Hawaii's Health QUEST. Chronically ill and disabled populations are exempted from these programs currently. New York State has applied for a Section 1115 waiver to develop, among other programs, a Special Needs Plan for "certain high-cost, high-need populations," including 100,000 HIV/AIDS patients. This proposal is still pending, as of February 5, 1996. (Center for State Policy Research, Medicaid Managed Care Analysis [Washington, D.C.: Center for State Policy Research], 5.)

\section{"Wendy Herr, "Medicaid and Managed Care Can Work Together," Health Care Financial Management 49, no, 7 (1995): 24.}

${ }^{21}$ As of September 1995, sixteen states use the 1915(c) waiver authority to provide enhanced services, including case management, personal care services, adult day health services, respite care, nursing, nutritional supplements, and homemaker/home health aide services for people with HIV/AIDS. California, Colorado, Delaware, Florida, Hawaii, Illinois, Iowa, Missouri, New Jersey, New Mexico, North Carolina, Pennsylvania, South Carolina, Virginia, and Washington have approved 1915(c) waiver programs which specifically target Medicaid beneficiaries with HIV/AIDS. Additionally, both Illinois and North Carolina support waiver programs that target the Medicaid disabled population and include HIV/AIDS patients as part of this group. Illinois has two such programs; North Carolina has one; Ohio also has a program. (Health Care Financing Administration, $1915(\mathrm{c})$ Home- and 
Community-Based Waivers, [Washington, D.C.: Department of Health and Humans Services], 11 September 1995.)

${ }^{22}$ Established in 1989, this Preferred Provider Organization (PPO) now provides care to approximately 300 patients in the greater Boston area, and is considering expanding its services to other special needs populations. Capitation under the Medicaid program provides the much-needed flexibility for CMA and allows the organization to control spending. For AIDS patients, for example, CMA has reduced the expenditures on inpatient hospital care, while increasing the amount spent on home infusion therapy. CMA has also increased the percentage of AIDS patients who die at home, rather than in the hospital. (Dan Wise, "Mass Managed Care Plan Reduces Hospital Costs for Patients with AIDS, Serve Disabilities," State Health Watch: The Newsletter on State Health Care Reform 2, no. 8 [August 1995] :1.) A Preferred Provider Organization (PPO) is a health plan that contracts with providers for services on a discounted fee-for-service basis or a negotiated fee schedule. Members pay lower deductibles or co-payments when they receive services from any of the "preferred. providers." Unlike other types of managed care plans, PPO providers usually do not share office space or administrative staff and may belong to any of several PPOs independent of other providers. (Aseltyne, S12.)

${ }^{23}$ Although capitation rates for people with AIDS rose from $\$ 4,100$ to $\$ 4,398$ in 1995 , CMA attributes this increase to the special needs of its population, as many patients require costly treatment for mental illness and substance abuse in addition to AIDS. (Wise, 1.)

${ }^{24}$ Gay Men's Health Crisis and AIDS Action Council (GMHC) a non-profit organization that relies primarily on private funding to provide a broad spectrum of services for people with HIV/AIDS. Such services include case management, nutrition counseling, financial and legal advocacy, and support groups, The organization-the oldest and largest of its kind in New York City-serves approximately one quarter of the AIDS population in New York City, home to roughly 17 percent of the nation's AIDS cases. (Susan Dooha, Senior Policy Associate, Gay Men's Health Crisis, phone interview, 16 November 1995.) GMHC influences public policy at all levels of government by participating in coalitions with other interest groups such as the AAC, which promotes and monitors legislation on all aspects of AIDS issues, (Congressional Quarterly, Inc., "Who's Who in Washington Non-Profit Groups," 1994.)

${ }^{25}$ The Office of National AIDS Policy is responsible for coordinating and representing the policy of the Executive Office of the President with respect to HIV/AIDS and oversees any Executive Office activities related to HIV/AIDS.

${ }^{26}$ These guidelines have been drafted for Medicaid managed care waiver applications and focus on the concerns of chronic illness populations, including HIV/AIDS patients. The questions focus on three issues: the specific health care needs of the chronic illness population (including access to care and the benefit structure offered); the evaluation of such applications with regard to the sensitive needs of these patients; and the existence of appropriate consumer protection for these populations. (Levi, Office of National AIDS Policy, internal memo.)

${ }^{27}$ These provisions are tailored to the needs of HIV/AIDS patients and focus on specific aspects of quality of care, including adequate provider networks, continuum of care maintenance, provision of necessary specialty care, and legal protection for HIV/AIDS patients in managed care. (Gay Men's Health Crisis and AIDS Action Council, 4.)

${ }^{28}$ Levi, interview with the author, 25 March 1996.

${ }^{29}$ Title I of Public Law 101-381 awards grants to Eligible Metropolitan Areas (EMAs) based on the number of reported AIDS cases per capita. These EMAs may then allocate funds to public or non-profit entities, including hospitals, communitybased organizations, hospices, ambulatory care facilities, community health centers, migrant health centers, and homeless health centers. This federal aid is to be used for "delivering or enhancing HIV-related outpatient and ambulatory health and support services" and limited inpatient case management services. Title II awards grants to all fifty states, the District of Columbia, Puerto Rico, and the territories based on the number of reported AIDS cases per capita. These grants are to be used to improve the quality of health care and support services for HIV patients, specifically home- and communitybased care and preventive services. These funds may not be used for inpatient hospital services, nursing home, or other long-term care facilities. Both titles prohibit the use of funds for services reimbursable under Medicaid or other programs in most instances. (Health Resources and Services Administration, Information About the Ryan White Comprebensive AIDS Resources Emergency Act of 1990: the Care Act, Public Law 101-381, August 18, 1990 [Washington, D.C.: Department of Health and Human Services, 1995], 2-9.)

${ }^{30}$ Health Resources and Services Administration, an agency of the Department of Health and Human Services, administers the Ryan White Comprehensive AIDS Resources Emergency Act of 1990, which provides federal funding for direct medical and social services to people infected with HIV or living with AIDS. In fiscal year 1994, HRSA allocated approximately $\$ 579$ million in federal money, roughly 15 percent of the aggregate public funds spent on HIV/AIDS health care services to states, localities, municipalities, and community-based organizations. (Medicaid's Role, Kaiser Commission on the Future of Medicaid.)

${ }^{31}$ Although Medicaid managed care arrangements come in many forms, two primary models (as defined by the Kaiser Commission on the Future of Medicaid) are fee-for-service primary care case management (PCCM), and full-risk plans. PCCM systems designate a specific provider, usually the patient's primary care physician, as a "gatekeeper" by approving and monitoring all covered services. In the case of an HIV/AIDS patient, the case manager would provide basic primary care services and would approve any specialty care in exchange for a monthly case management fee, and a separate fee for each service provided. Since PCCM providers do not assume financial risk for the provision of such services, they do not have strong incentives to control costs. Under a fullrisk or "fully capitated" plan, the state Medicaid program contracts with a corporate entity which provides a set of services 
through a designated provider network for a fixed monthly fee. The corporation may shift some of the financial risk by subcontracting with hospitals and other providers. Thus, both the corporate entity and the providers have an incentive to contain health care costs. An HIV/AIDS patient would be required to receive primary care from a list of providers whose referral would also be required for specialty care. In some cases, the patient would be permitted to see a specialist outside of the plan, but only on a fee-for-service basis. Additionally, the plan may exclude certain types of experimental treatment from coverage or limit benefits such as the length of hospital stays. These types of practices discourage the use of specialty care which can reduce health care expenditures. (Kaiser Commission, Policy Brief: The Kaiser Commission on the Future of Medicaid, 3-4.) The Kaiser Commission on the Future of Medicaid is a policy institute established by the Henry J. Kaiser Foundation in 1991. The Foundation is an independent national health care philanthropy and not associated with Kaiser Permanente or Kaiser Industries. (Diane Rowland Sara Rosenbaum, Lois Simon, and Elizabeth Chait, Medicaid and Managed Care: Lessons from Literature [Washington, D.C.: The Kaiser Commission on the Future of Medicaid, 1995].) Health administrators and advocacy groups are concerned that, in their efforts to contain costs, full-risk plans may underserve patients who require expensive treatment, like those with HIV/AIDS. (Rhonda Fisher, "Medicaid Managed Care: The Next Generation?," Academic Medicine 69, no.5 (1994): 317.) On the other hand, full-risk plans have the ability to coordinate the services of several providers, an important benefit for HIV/AIDS patients. (Aseltyne, 512.) The major type of full-risk plan is the Health Maintenance Organization (HMO), in which the providers and the corporate entity are integrated into one plan. The other type of full-risk plan, the Health Insuring Organization (HIO), operates as a fiscal intermediary and is not integrated with the provider network that actually delivers the services. (Kaiser Commission, "Policy Brief," 3-4.)

${ }^{32}$ Aseltyne, S12.

${ }^{33}$ Aseltyne, S16. "Off-label" use of prescription drugs implies prescribing drugs for uses beyond what the Food and Drug
Administration has approved. This type of treatment is one of many experimental interventions used by physicians to attack HIV/AIDS.

${ }^{31}$ Ibid, S18.

${ }^{35}$ Ibid, S11.

${ }^{36}$ Although performance measurement is still underdeveloped for people with HIV/AIDS, there are some fundamental measures which can indicate the result of managed care programs. For example, in monitoring care for people with HIV, one possible outcome indicator is the occurrence of treatable opportunistic infections, such as pneumonia, which pose the greatest threat to HIV-infected people. Such infections can be prevented if the patient's T-cells are counted regularly and a prophylactic drug is administered when necessary. The medication, which can prevent opportunistic infections, is inexpensive when compared to the treatment necessary after the patient becomes infected which can cost as much as $\$ 10,000$ per episode. (Levi, interview with author, 4 December 1995.)

${ }^{37}$ The Health Care Financing Administration, a division of the Department of Health and Human Services, oversees both the Medicaid and Medicare programs. The agency's Medicaid Bureau reviews state waiver applications, assists in the implementation of demonstration programs, and evaluates these programs. The Bureau staff have shown a strong interest in containing the rising costs of Medicaid through innovative strategies and are willing to explore alternatives for beneficiaries with HIV/AIDS. The Bureau is also supportive of states" efforts to reduce the costs of care for Medicaid beneficiaries through the use of managed care organizations, but closely monitors these new programs to ensure that the quality of care is maintained. (Rachel Block, Associate Director, Medicaid Bureau, Health Care Financing Administration, discussion and interview with author, 31 October 1995.)

${ }^{38}$ Although many states are already implementing Medicaid managed care programs, outcome data are difficult to collect. Many states do not have the time and resources necessary for sophisticated data collection systems, and very little data is collected in a uniform fashion.

\section{Bibliography}

The Albany (New York) Times Union, 18 February 1996.

American Political Network, Inc. Health Line. New York: Feds Seek More Information on NYC Medicaid Waiver. American Political Network, Inc.,12 October 1995.

Health Line. New York: Officials Will Proceed with Statewide Waiver. American Political Network, Inc., 31 October 1995.

Aseltyne, William J. et al. "HIV Disease and Managed Care: An Overview." Joumal of Acquired Immune Deficiency Syndromes and Human Retrovirology 8, supplement no. 11 (1995).

The Boston Globe, 13 December 1995.
Bozzette, Samuel A. and Steven Asch. "Developing Quality Review Criteria from Standards of Care for HIV Disease: A Framework." Journal of Acquired Immune Deficiency Syndrome and Human Retrovirology 8, supplement no.1 (1995): S45-52.

Buchanan, Robert J. and Fred G. Kircher. "Medicaid Policies for AIDS-Related Hospital Care." Healtb Care Financing Review 15, no. 4 (1994): 33-41.

Bureau of National Affairs, Inc. BNA Health Care Daily. New York City HMOs Not Ready to Serve HIV-Positive Women, Children, Study Says. Washington D.C.: Bureau of National Affairs, Inc., 13 October 1995.

Center for State Policy Research. Medicaid Managed Care Analysis, Washington, D.C., February 1996. 
- Medicaid Managed Care Analysis. Washington, D.C., February, 1996.

Clements, Joe. "Blues, CMA Link to Provide Home AIDS Care." Boston Business Journal (13 August 1990): 5.

Commerce Clearing House. "AIDS Patients to be Hit Hard by GOP Plan." Pulse: The Health Care Reform Newsletter 3, no. 43 (1995): 10.

"States Receive Higher Grants, but Governors, White House Raise." Pulse :The Health Care Reform Newsletter 3 , no. 44 (1995): 6.

. "Block Grants Would Harm Some State Health Programs." Pulse. The Health Care Reform Newsletter 3 , no. 45 (1995): 8.

- "Medicaid/Medicare Provisions in the Balanced Budget Act of 1995." Pulse: The Health Care Reform Newsletter 3 , no. 47 (1995): 7 .

The Daily News, an Internet news service, 5 October 1995.

Department of Health \& Human Services, Health Care Financing Administration, Office of Managed Care, Medicaid Managed Care Office. Medicaid Managed Care Enrollment Report: Summary Statistics as of June 30, 1994. Washington, D.C.: Department of Health and Human Services, 1994.

. National Summary of State Medicaid Managed Care Programs: Program Descriptions as of June 30, 1994. Washington, D.C.: Department of Health and Human Services, 1994.

. Comprebensive Section 1115 Demonstration Projects. Washington, D.C.: Department of Health and Human Services, 11 July 1994.

. Medicaid and AIDS. Washington, D.C.: Department of Health and Human Services, 1995.

1915(c) Home- and Community-based Waivers (unpublished draft, 11 September 1995).

Department of Health and Human Services, Public Health Service, Centers for Disease Control. Morbidity and Mortality Weekly Report 44, no. 46. Washington, D.C.: Department of Health and Human Services, 24 November 1995.

Department of Health and Human Services, Public Health Service, Health Resources and Services Administration, Bureau of Health Resources Development. Information About the Ryan White Comprebensive AIDS Resources Emergency Act of 1990. The Care Act, Public Law 101-381, August 18, 1990. Washington, D.C.: Department of Health and Human Services, June 1995.

Fisher, Rhonda. "Medicaid Managed Care: The Next Generation?" Academic Medicine 69, no. 5 (1994).

Gardner, Jonathan. "AIDS/HIV Care Proving Costly for Hospitals." Modern Healtbcare 25, no.23 (1995): 6.

Gay Men's Health Crisis and AIDS Action Council. Review of State Medicaid Managed Care Waiver Applications by the
Health Care Financing Administration: Impact on Recipients with HIV and AIDS. New York: AIDS Action Council and Gay Men's Health Crisis.

General Accounting Office. Medicaid: Spending Pressures Drive States Toward Program Reinvention. GAO/HEHS-95122. Washington, D.C.: General Accounting Office, April 1995.

Hegner, Richard E. Section 1115 Medicaid Waivers: Demonstrations or Strategy for Incremental Reform? Issue Brief No. 662. Washington, D.C.: National Health Policy Forum.

Hellinger, Fred J. "The Lifetime Cost of Treating a Person with HrV." Journal of the American Medical Association 270, no. 4 (1993): 474.

Henry J. Kaiser Family Foundation, The. Policy Brief: The Kaiser Commission on the Future of Medicaid. Washington, D.C.: The Henry J. Kaiser Family Foundation, June 1995.

Medicaid's Role for Persons with HIV/AIDS. Washington, D.C.: The Henry J. Kaiser Family Foundation.

Herr, Wendy. "Richardson: Medicald and Managed Care Can Work Together." Healthcare Financial Management 49, no. 7 (1995): 24-28.

Holahan, John et al. "Insuring the Poor Through Section 1115 Medicaid Waivers." Health Affairs 14, no. 1 (1995): 199-217.

Iglehart, John K. "Health Policy Report: Medicaid and Managed Care." New England Journal of Medicine 332, no. 25 (1995): 1727-1730.

Japsen, Bruce. "AIDS Gets Managed-Care Approach." Modern Healthcare 24, no. 43 (1994).

"In a Tough Climate, AIDS Groups Seek More Funds." Modern Healtbcare 25, no. 1 (1995).

"California Group's Capitated AIDS-Care Plan Launched." Modern Healtbcare 25, no. 16 (1995).

Office of National AIDS Policy. The HIV/AIDS Pandemic-Why Continued Funding is Needed. Office of National Aids Policy, internal document, photocopy.

Perkins, Jane and Michele Melden. Section 1115 Medicaid Waivers: An Advocate's Primer. National Health Law Program, October 1994.

Physician Payment Review Commission. Medicaid Demonstrations. Annual Report to Congress Physician Payment Review Commision,1995, mimeographed.

Nassau and Suffolk Edition (New York) Newsday, 27 February 1996.

The New York Times, 4 October 1995.

The New York Times, 5 October 1995.

The New York. Times, 11 October1995.

The New York Times, 28 October 1995. 
Riley, Trish. "State Health Reform and the Role of 1115 Waivers." Health Care Financing Review 16, no. 3 (Spring 1995): 139-151.

Robert Wood Johnson Foundation, The. Cbronic Care Inttiatives in HMOs. Washington, D.C.: The Robert Wood Johnson Foundation, 1995.

Rosenbaum, Sarah, J.D. and Julie Darnell M.H.S.A. The George Washington University, Center for Health Policy Research. Medicaid Section 1115 Demonstration Waivers: Approved and Proposed Activities as of February 1995. Washington, D.C.: The Kaiser Commission on the Future of Medicaid, February 1995.

Rowland, Diane, Sara Rosenbaum, Lois Simon, and Elizabeth Chait. Center for Health Care Policy Research. The George Washington University. Medicaid and Managed Care: Lessons from the Literature. Washington, D.C.: The Kaiser Commission on the Future of Medicaid, March 1995.
Rotwein, Susan, et al. "Medicaid and State Health Care Reform: Process, Programs and Policy Options." Health Care Financing Review 16, no. 3 (Spring 1995); 105-120.

Thorne, Jean I. et al. "State Perspectives on Health Care Reform: Oregon, Hawaii, Tennessee, and Rhode Island." Healtb Care Financing Review 16, no. 3 (1995).

The Wasbington Post, 8 December 1995.

Weissenstein, Eric. "Medicaid Managed Care Might Not Result in Savings-Study." Modern Healtbcare 23, no. 2 (1993): 8.

Wilensky, Gail R., Ph.D. "Financing Care for Patients with AIDS." Journal of the American Medical Association 266, no. 24 (1991): 3404.

Wise, Dan. "Mass, Managed Care Plan Reduces Hospital Costs for Patients with AIDS, Severe Disabilities." State Health Watcb: The Newsletter on State Healtb Care Reform 2, no. 8 (August 1995). 